\title{
Comparison of propofol alone and in combination with ketamine or fentanyl for sedation in endoscopic ultrasonography
}

\author{
Shweta A Singh ${ }^{1}$, Kelika Prakash ${ }^{1}$, Sandeep Sharma ${ }^{1}$, Gaurav Dhakate ${ }^{1}$, and \\ Vikram Bhatia ${ }^{2}$ \\ Departments of ${ }^{1}$ Anaesthesiology and Critical Care and ${ }^{2}$ Hepatology, Institute of Liver \& Biliary Sciences, New \\ Delhi, India
}

\begin{abstract}
Background: We evaluated whether the addition of a small dose of ketamine or fentanyl would lead to a reduction in the total dose of propofol consumed without compromising the safety and recovery of patients having endoscopic ultrasonography (EUS).

Methods: A total of 210 adult patients undergoing elective EUS under sedation were included in the study. Patients were randomized into three groups. Patients were premedicated intravenously with normal saline in group 1,50 $\mu \mathrm{g}$ fentanyl in group 2 , and $0.5 \mathrm{mg} / \mathrm{kg}$ ketamine in group 3. All patients received intravenous propofol for sedation. Propofol consumption in $\mathrm{mg} / \mathrm{kg} / \mathrm{h}$ was noted. The incidence of hypotension, bradycardia, desaturation, and coughing was noted. The time to achieve a Post Anesthesia Discharge Score (PADS) of 10 was also noted.

Results: There were 68 patients in group 1, 70 in group 2, and 72 in group 3. The amount of propofol consumed was significantly higher in group $1(9.25[7.3-13.2])$ than in group $2(8.8[6.8-12.2])$ and group $3(7.6[5.7-9.8])$. Patient hemodynamics and oxygenation were well maintained and comparable in all groups. The time to achieve a PADS of 10 was significantly higher in group 3 compared to the other two groups.

Conclusions: The use of $50 \mu \mathrm{g}$ fentanyl or $0.5 \mathrm{mg} / \mathrm{kg}$ ketamine in a single dose during EUS reduces the dose of propofol required for sedation. However, unlike the addition of fentanyl, the addition of ketamine increased the time to recovery. Thus, $50 \mu \mathrm{g}$ fentanyl is a good additive to propofol infusion for sedation during EUS to reduce the requirement for propofol without affecting the time to recovery.
\end{abstract}

Keywords: Endoscopic ultrasonography; Fentanyl; Ketamine; Propofol; Sedation.

Corresponding author: Shweta A Singh, M.D.

Department of Anaesthesiology and Critical Care, Institute of Liver \& Biliary Sciences, Vasant Kunj, New Delhi 110070, India

Tel: 91-9810625177, Fax: 91-1126123504

Email: drshwetasingh29@gmail.com

ORCID: https://orcid.org/0000-0002-9339-8526

Received: December 14, 2016.

Revised: February 28, 2017 (1st); April 3, 2017 (2nd).

Accepted: April 16, 2017.

Korean J Anesthesiol 2018 February 71(1): 43-47

https://doi.org/10.4097/kjae.2018.71.1.43

\section{Introduction}

Endoscopic ultrasonography (EUS) is an outpatient procedure that combines endoscopy with ultrasound. During an EUS procedure, an upper gastrointestinal (GI) scope is inserted into the esophagus through the mouth to obtain ultrasonographic as well as endoluminal images of various upper gastrointestinal pathologies. The probe has a channel that enables ultrasound-guided fine needle aspiration cytology (FNAC) of suspicious lesions to be performed at the same time. The distal end of the EUS probe has a longer, stiffer section than conventional

(c) This is an open-access article distributed under the terms of the Creative Commons Attribution Non-Commercial License (http://creativecommons.org/ licenses/by-nc/4.0/), which permits unrestricted non-commercial use, distribution, and reproduction in any medium, provided the original work is properly cited. 
endoscopes and therefore needs extra care during manipulation through the gastrointestinal tract. Further, the diameter of the EUS probe is greater than that of conventional endoscopes, at around 13-14 $\mathrm{mm}$ compared to $8-10 \mathrm{~mm}$. The procedure usually takes between $30 \mathrm{~min}$ and $1 \mathrm{~h}$. Patients are sedated to keep them comfortable during the procedure and to help them tolerate the scope.

Propofol is a common sedative agent for outpatient procedures because of its advantageous pharmacokinetic properties, which include a quick and clear-headed recovery $[1,2]$. However, at deeper levels of sedation, propofol can lead to loss of airway reflexes, hypotension, cardio-respiratory depression, and even apnea. In addition, during EUS, the scope hinders swallowing of saliva, thereby increasing the chance of aspiration.

Attempts have been made in the past to use additives with propofol to reduce its dose. In one study, a combination of midazolam with propofol resulted in reducing the dose of propofol as well as better amnesia in outpatient surgeries [3]. In a study on patients undergoing endoscopic retrograde choliopancreatography, Paspatis et al. [4] showed that the group receiving propofol alone not only had higher anxiety levels but also had a significantly greater number of desaturation $\left(\mathrm{SpO}_{2}<90 \%\right)$ episodes. Further, it has been shown that during colonoscopies, propofol in combination with fentanyl provided similar patient satisfaction with shorter recovery times even at lower depths of sedation as compared to propofol [5]. The addition of a median dose of $50 \mu \mathrm{g}$ of fentanyl to propofol has been shown to result in better operator feasibility with no difference in recovery time, cognitive impairment, or complications as compared to the use of propofol only for sedation [6]. A meta-analysis of sedation protocols concluded that propofol in combination with ketamine decreased respiratory complications and reduced cardiovascular complications (hypotension and bradycardia) during procedural sedation and analgesia [7]. However, studies on ideal sedation technique in EUS are scarce. As there are compounding factors compromising the airway during EUS, we performed this double-blind randomized controlled trial to compare the use of propofol alone and in combination with ketamine or fentanyl for sedation during EUS.

\section{Aim}

The primary outcome was to evaluate the effect of the addition of fentanyl and ketamine on propofol consumption ( $\mathrm{mg} / \mathrm{kg} / \mathrm{h})$.

Secondary outcomes were as follows:

1. To evaluate the time to achieve a Post Anesthesia Discharge Score (PADS) of 10.

2. To evaluate the hemodynamic profile and adverse effects in the three groups.

\section{Materials and Methods}

This was a randomized double-blind controlled study conducted in a tertiary center (CTRI/2016/11/007463). After obtaining Institutional Review Board approval, adult (18-60 years) consenting patients of American Society of Anesthesiologists physical status classification I/II and of either gender who were scheduled for abdominal EUS and FNAC by a single endoscopist were enrolled in the study. Patients who were allergic to propofol, those who were taking antipsychotic medications, and pregnant or lactating women were excluded from the study group. Patients were randomized using a computer-generated random sheet into three groups. All procedures were performed by a single endoscopist who was blinded to the groups. All patients were positioned in the left lateral position before sedation. Electrocardiogram, pulse oximetry, and noninvasive blood pressure were monitored, and oxygen at $4 \mathrm{~L} / \mathrm{min}$ was supplemented using nasal prongs. All patients received $1 \mathrm{mg}$ of intravenous midazolam $10 \mathrm{~min}$ prior to the procedure. In addition, patients in Group 1 received saline, those in Group 2 received $50 \mu \mathrm{g}$ of fentanyl, and those in Group 3 received $0.5 \mathrm{mg} / \mathrm{kg}$ of ketamine [8] premixed with $0.02 \mathrm{mg}$ of glycopyrrolate intravenously, 5 min prior to the procedure. All premedication was prepared in identical syringes. Normal saline was added to make up a total volume of $5 \mathrm{cc}$. Propofol was then administered intravenously and titrated to loss of verbal response, after which the endoscope was inserted. Sedation was maintained at Ramsay sedation scale 2 with an infusion of propofol at $50 \mu \mathrm{g} / \mathrm{kg} / \mathrm{min}$, which was titrated upward to a maximum dose of $150 \mu \mathrm{g} / \mathrm{kg} / \mathrm{min}$ by the anesthesiologist as per the requirement. The sedation scale was checked by the response to verbal command and glabellar tap every 5 minutes. Hemodynamic parameters were monitored at 5 -min intervals. Adverse events including desaturation $\left(\mathrm{SpO}_{2}\right.$ $<95 \%$ ), hypotension (mean blood pressure $<20 \%$ of baseline), and coughing were noted. Desaturation that could be managed by jaw thrust and suctioning was classified as minor, and cases requiring placement of an advanced airway were classified as major adverse events. Hypotension managed with $6 \mathrm{mg}$ of intravenous ephedrine or a fluid bolus of $200 \mathrm{cc}$ of plasmalyte was classified as a minor adverse event. Episodes of hypotension managed with noradrenaline infusion were classified as major adverse events. In addition, as certain studies have reported an increase in the occurrence of hiccups when endoscopic procedures are performed under sedation, we noted the incidence of hiccups in the three groups [9]. At the end of the procedure, total propofol consumption was recorded. The endoscopist was asked to rate operator feasibility as poor, average, or good. This was a subjective rating made by the single endoscopist for which no objective criteria were given. The rating was based on the quality of sedation and interruptions during the procedure 
for airway management and hiccups. Post procedure, patients were monitored in the recovery room every $15 \mathrm{~min}$, and time to achieve a PADS of 10 was noted. At the time of discharge from the recovery room, patient feedback was obtained on recall of the procedure.

\section{Statistical analysis}

Data were analyzed using IBM SPSS Statistic 20 (IBM Corp., Armonk, NY, USA). Descriptive statistics were presented as percent/proportion for discrete variables. Mean \pm SD or median and interquartile range (IQR) were used for continuous variables. In inferential statistics, chi square was applied for discrete variables. For continuous normally distributed data, ANOVA was applied. The Kruskal-Wallis test was applied for non-normally distributed data. Intergroup analysis between two groups was performed using the Student's $t$ test for parametric data and the Mann-Whitney test for non-parametric data. Thus, as the amount of propofol consumed was non-parametric, the Kruskal-Wallis test was used followed by the Mann-Whitney test for intergroup analysis. The time to achieve a PADS of 10 was parametric and was therefore analyzed using ANOVA followed by Student's $t$ test. A P value of $<0.05$ was considered to be significant.

\section{Results}

A total of 210 adult patients scheduled for elective EUS under sedation by a single endoscopist were included in the study between December 2013 and July 2015. One hundred twelve (53.3\%) patients were male and 98 (46.7\%) were female. There were 68 patients in group 1, 70 in group 2, and 72 in group
3. The demographic characteristics of the three groups were comparable (Table 1). All procedures were completed without major adverse events. The duration of the procedure in the three groups was comparable (Table 1).

The primary outcome was the amount of propofol consumed. The median propofol consumed was 9.25 (IQR 7.3-13.2) mg/ $\mathrm{kg} / \mathrm{h}$ in the propofol-only group (group 1), 8.8 (IQR 6.8-12.2) $\mathrm{mg} / \mathrm{kg} / \mathrm{h}$ in the fentanyl group (group 2), and 7.6 (IQR 5.7-9.8) $\mathrm{mg} / \mathrm{kg} / \mathrm{h}$ in the ketamine group (group 3) (Table 2). Statistical analysis by the Kruskal-Wallis test showed that this difference was significant $(\mathrm{P}=0.008)$. Intergroup comparison with nonparametric tests showed that propofol consumption was significantly higher in group 1 than in group $2(\mathrm{P}=0.024)$ or group $3(\mathrm{P}<0.001)$. However, there was no significant difference in propofol consumption between group 2 and group $3(\mathrm{P}=0.391)$.

One of the secondary outcomes was the time to achieve a maximum PADS of 10. A significant difference was noted when ANOVA was used $(\mathrm{P}<0.001)$. On further intergroup analysis, it was observed that this was longest in group 3, the ketamine group $(46.3 \pm 15.4 \mathrm{~min})$, and was also statistically significantly higher than in group $2(37.1 \pm 14.6 \mathrm{~min}, \mathrm{P}=0.001)$ or group 1 (32.9 $\pm 13.9 \mathrm{~min}, \mathrm{P}<0.001)$ (Table 2$)$. There was no difference in the time taken to achieve a PADS of 10 between group 1 and group $2(\mathrm{P}=0.280)$. Mean blood pressure, heart rate, and $\mathrm{SpO}_{2}$ were analyzed at 5-min intervals. Overall, patient hemodynamics and oxygenation were comparable in all groups. There were no significant differences in the mean blood pressure, heart rate, or $\mathrm{SpO}_{2}$ at any time point among the three groups (Fig. 1). There were also no differences in the incidence of desaturation $(\mathrm{P}$ $=0.922)$, hypotension $(\mathrm{P}=0.880)$, coughing $(\mathrm{P}=0.269)$, or hiccups $(\mathrm{P}=0.727)$ among the three groups (Table 3$)$. No patient in any group needed the placement of an airway or noradrenaline

Table 1. Demographic Characteristics

\begin{tabular}{lcccc}
\hline & Group 1 & Group 2 & Group 3 & P value \\
\hline Age $(\mathrm{yr})^{*}$ & $45.9 \pm 15.6$ & $49.3 \pm 14.5$ & $44.4 \pm 16.4$ & 0.425 \\
Gender (M/F) & $46 / 22$ & $39 / 31$ & $46 / 26$ & 0.333 \\
ASA I/II & $16 / 52$ & $18 / 52$ & $16 / 56$ & 0.252 \\
\hline
\end{tabular}

*Values are given as mean \pm SD. Patients in Group 1 received propofol only, Group 2 received fentanyl + propofol, and Group 3 received ketamine + propofol. ASA: American Society of Anesthesiologists physical status classification.

Table 2. Propofol Consumption, Time to Achieve PADS of 10, and Duration of Procedure

\begin{tabular}{|c|c|c|c|c|}
\hline & Group 1 & Group 2 & Group 3 & $P$ value \\
\hline Propofol $(\mathrm{mg} / \mathrm{kg} / \mathrm{h})^{\dagger}$ & $9.25(7.3-13.2)$ & $8.8(6.8-12.2)$ & $7.6(5.7-9.8)$ & $0.008^{\ddagger}$ \\
\hline Time to achieve PADS $10^{*}$ & $32.9 \pm 13.9$ & $37.1 \pm 14.6$ & $46.3 \pm 15.4$ & $<0.001^{\ddagger}$ \\
\hline Duration of procedure $(\min )^{+}$ & $40(28.2-55)$ & $39(24-52.2)$ & $39(28.7-50)$ & 0.500 \\
\hline
\end{tabular}

*Values are given as mean $\pm \mathrm{SD} .{ }^{\dagger}$ All values are given as median (interquartile range). ${ }^{\dagger} \mathrm{P}<0.05$. Patients in Group 1 received propofol only, Group 2 received fentanyl + propofol, and Group 3 received ketamine + propofol. PADS: Post Anesthesia Discharge Score. 

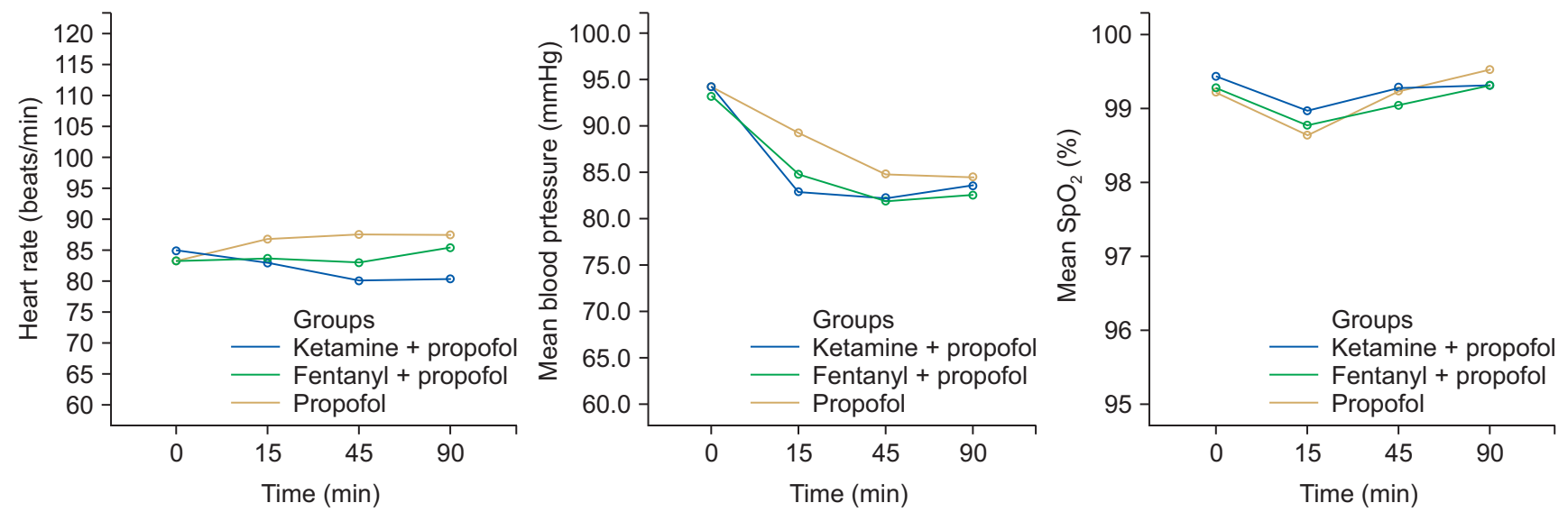

Fig. 1. Line diagram representing the average heart rate, average mean blood pressure, and average $\mathrm{SpO}_{2}$ in different groups at different time points during the study period.

Table 3. Number of Patients Exhibiting Adverse Events

\begin{tabular}{lrcc}
\hline Adverse event & $\begin{array}{r}\text { Group 1 } \\
(\mathrm{n}=68)\end{array}$ & $\begin{array}{c}\text { Group 2 } \\
(\mathrm{n}=70)\end{array}$ & $\begin{array}{c}\text { Group 3 } \\
(\mathrm{n}=72)\end{array}$ \\
\hline Desaturation & $5(7.35 \%)$ & $4(5.71 \%)$ & $5(6.94 \%)$ \\
Hypotension & $4(5.88 \%)$ & $4(5.71 \%)$ & $3(4.16 \%)$ \\
Coughing & $2(2.94 \%)$ & $5(7.14 \%)$ & $7(9.72 \%)$ \\
Hiccups & $24(35.2 \%)$ & $28(40 \%)$ & $30(41.67 \%)$ \\
\hline
\end{tabular}

Values are given as number (\%). Patients in Group 1 received propofol only, Group 2 received fentanyl + propofol, and Group 3 received ketamine + propofol.

infusion. Thus, there were no major side effects in any patient in any group. All patients in the three groups were discharged from the recovery room after $2 \mathrm{~h}$ of observation as per institutional guidelines. No patient had any recall or memory after the procedure. There was no difference in operator feasibility in the groups as rated by the endoscopist $(\mathrm{P}=0.595)$ (Table 4$)$.

\section{Discussion}

Propofol has been extensively used for sedation in endoscopic procedures [4]. It is a $\gamma$-aminobutyric acid facilitator in the central nervous system. Its suitable pharmacokinetic profile along with its ability to facilitate a clear-headed recovery make it a good sedative agent for outpatient procedures. However, it has no analgesic properties and at higher doses it can lead to the loss of protective airway reflexes, hypotension, and bradycardia. These side effects, compounded by the fact that during EUS anesthetists are dealing with a shared airway, necessitate that propofol be used in the lowest possible doses. Common adjuncts to propofol include benzodiazepines like midazolam, opioids, and ketamine. Fentanyl is an opioid and has good analgesic as well as sedative properties. It is a hemodynamically stable drug
Table 4. Operator Feasibility

\begin{tabular}{lccc}
\hline & $\begin{array}{c}\text { Group 1 } \\
(\mathrm{n}=68)\end{array}$ & $\begin{array}{c}\text { Group 2 } \\
(\mathrm{n}=70)\end{array}$ & $\begin{array}{c}\text { Group 3 } \\
(\mathrm{n}=72)\end{array}$ \\
\hline Good & 60 & 62 & 60 \\
Average & 8 & 8 & 12 \\
Poor & 0 & 0 & 0 \\
\hline
\end{tabular}

Patients in Group 1 received propofol only, Group 2 received fentanyl + propofol, and Group 3 received ketamine + propofol.

with an onset of action of 7 to $8 \mathrm{~min}$ and duration of 1 to $2 \mathrm{~h}$. It is often combined with propofol or midazolam to provide sedation for outpatient procedures [10,11]. On the other hand, ketamine acts on N-methyl-D-aspartate receptors and produces dissociative anesthesia. Unlike other sedatives, it preserves airway reflexes. Side effects include increased secretions and agitation on recovery. To counter the side effects, we administered glycopyrrolate in the ketamine group along with midazolam as premedication. Increased salivation can be problematic especially during upper GI endoscopic procedures in which the patient is unable to swallow due to the presence of the scope. Midazolam was administered to prevent agitation during recovery from ketamine [12].

Singh et al. [13] in 2013 compared the adjuvant effect of fentanyl and ketamine in patients undergoing laparoscopic tubal ligation in an outpatient setting and found that the fentanyl combination was associated with faster recovery and better patient satisfaction as compared to ketamine-propofol. However, in 2010, Tang et al. [14] found that the addition of low-dose ketamine to propofol-fentanyl sedation provided more stable and satisfactory operating conditions in gynecologic diagnostic laparoscopy. However, the above two studies involved surgical procedures, unlike EUS, which is a minimally invasive endoscopic procedure. 
Ketamine and propofol, when used in combination, have resulted in a lowering of the incidence of hypoxia and cardiovascular collapse (bradycardia and hypotension) associated with propofol when used alone [7]. Addition of ketamine to propofol has led to a reduction in the incidence of desaturation. However, these studies were not performed on patients undergoing upper GI endoscopy or EUS [15], who are at increased risk of airway compromise [16]. Hence, we evaluated whether the addition of ketamine or fentanyl in a small single dose to propofol infusion for sedation during EUS resulted in a decrease in propofol consumption. In line with previous studies, in the present study, we found that the addition of either $50 \mu \mathrm{g}$ of fentanyl or $0.5 \mathrm{mg} / \mathrm{kg}$ of ketamine resulted in a significant decrease in the amount of propofol consumed (in $\mathrm{mg} / \mathrm{kg} / \mathrm{h}$ ). There was no difference in the dose of propofol used between the ketamine and fentanyl groups. Time taken to achieve PADS was significantly longer in the ketamine group; however, all patients were successfully discharged from the recovery room at the end of a 2-h observation period. There were no major adverse events in any of the three groups. This is in accordance with previous studies in which the use of either propofol with ketamine or propofol with fentanyl for deep sedation had comparable side effects with minor hemodynamic events [17].

Thus, we can conclude from the present study that the addition of fentanyl to propofol results in a decrease in propofol consumption with no increase in either the time to recovery or adverse effects. Fentanyl is thus a good additive to propofol for sedation during EUS. The addition of a single dose of ketamine reduced the total propofol requirement but delayed recovery.

\section{References}

1. Cohen LB, Delegge MH, Aisenberg J, Brill JV, Inadomi JM, Kochman ML, et al. AGA Institute review of endoscopic sedation. Gastroenterology 2007; 133: 675-701.

2. McQuaid KR, Laine L. A systematic review and meta-analysis of randomized, controlled trials of moderate sedation for routine endoscopic procedures. Gastrointest Endosc 2008; 67: 910-23.

3. Reinhart DJ, Grum DR, Berry J, Lensch D, Marchbanks CR, Zsigmond E. Outpatient general anesthesia: a comparison of a combination of midazolam plus propofol and propofol alone. J Clin Anesth 1997; 9: 130-7.

4. Paspatis GA, Manolaraki MM, Vardas E, Theodoropoulou A, Chlouverakis G. Deep sedation for endoscopic retrograde cholangiopancreatography: intravenous propofol alone versus intravenous propofol with oral midazolam premedication. Endoscopy 2008; 40: 308-13.

5. VanNatta ME, Rex DK. Propofol alone titrated to deep sedation versus propofol in combination with opioids and/or benzodiazepines and titrated to moderate sedation for colonoscopy. Am J Gastroenterol 2006; 101: 2209-17.

6. Padmanabhan U, Leslie K, Eer AS, Maruff P, Silbert BS. Early cognitive impairment after sedation for colonoscopy: the effect of adding midazolam and/or fentanyl to propofol. Anesth Analg 2009; 109: 1448-55.

7. Bellolio MF, Gilani WI, Barrionuevo P, Murad MH, Erwin PJ, Anderson JR, et al. Incidence of adverse events in adults undergoing procedural sedation in the emergency department: a systematic review and meta-analysis. Acad Emerg Med 2016; 23: 119-34.

8. Pai A, Heining M. Ketamine. Contin Educ Anaesth Crit Care Pain 2007; 7: 59-63.

9. Liu CC, Lu CY, Changchien CF, Liu PH, Perng DS. Sedation-associated hiccups in adults undergoing gastrointestinal endoscopy and colonoscopy. World J Gastroenterol 2012; 18: 3595-601.

10. Cohen LB, Hightower CD, Wood DA, Miller KM, Aisenberg J. Moderate level sedation during endoscopy: a prospective study using lowdose propofol, meperidine/fentanyl, and midazolam. Gastrointest Endosc 2004; 59: 795-803.

11. Hasen KV, Samartzis D, Casas LA, Mustoe TA. An outcome study comparing intravenous sedation with midazolam/fentanyl (conscious sedation) versus propofol infusion (deep sedation) for aesthetic surgery. Plast Reconstr Surg 2003; 112: 1683-9.

12. Green SM, Roback MG, Kennedy RM, Krauss B. Clinical practice guideline for emergency department ketamine dissociative sedation: 2011 update. Ann Emerg Med 2011; 57: 449-61.

13. Singh R, Ghazanwy M, Vajifdar H. A randomized controlled trial to compare fentanyl-propofol and ketamine-propofol combination for procedural sedation and analgesia in laparoscopic tubal ligation. Saudi J Anaesth 2013; 7: 24-8.

14. Tang YY, Lin XM, Huang W, Jiang XQ. Addition of low-dose ketamine to propofol-fentanyl sedation for gynecologic diagnostic laparoscopy: randomized controlled trial. J Minim Invasive Gynecol 2010; 17: 325-30.

15. Ulmer BJ, Hansen JJ, Overley CA, Symms MR, Chadalawada V, Liangpunsakul S, et al. Propofol versus midazolam/fentanyl for outpatient colonoscopy: administration by nurses supervised by endoscopists. Clin Gastroenterol Hepatol 2003; 1: 425-32.

16. Tosun Z, Esmaoglu A, Coruh A. Propofol-ketamine vs propofol-fentanyl combinations for deep sedation and analgesia in pediatric patients undergoing burn dressing changes. Paediatr Anaesth 2008; 18: 43-7.

17. Yan JW, McLeod SL, Iansavitchene A. Ketamine-propofol versus propofol alone for procedural sedation in the emergency department: a systematic review and meta-analysis. Acad Emerg Med 2015; 22: 1003-13. 